\title{
Assessment of the Virulence Spectrum and Its Association with Genetic Diversity in Magnaporthe oryzae Populations from Sub-Saharan Africa
}

\author{
S. K. Mutiga, F. Rotich, V. Devi Ganeshan, D. T. Mwongera, E. M. Mgonja, V. M. Were, J. W. Harvey, B. Zhou, L. Wasilwa, \\ C. Feng, I. Ouédraogo, G.-L. Wang, T. K. Mitchell, N. J. Talbot, and J. C. Correll
}

First, second, tenth, and fifteenth authors: Department of Plant Pathology, University of Arkansas-Fayetteville; first and seventh: Biosciences eastern and central Africa-International Livestock Research Institute (BecA-ILRI) Hub, Nairobi, Kenya; third, fifth, twelfth, and thirteenth authors: Department of Plant Pathology, The Ohio State University-Columbus; fourth, sixth, and fourteenth authors: Biosciences department, Exeter University, UK; seventh author: Feed the Future Innovation Lab for the Reduction of Post-Harvest Loss, Kansas State University, Manhattan, Kansas; eighth author: International Rice Research Institute (IRRI), Philippines; ninth author: Kenya Agricultural and Livestock Research Organization (KALRO), Nairobi, Kenya; and eleventh author: Institute of Environment and Agricultural Research, Ouagadougou, Burkina Faso. Accepted for publication 22 March 2017.

\begin{abstract}
A collection of 122 isolates of Magnaporthe oryzae, from nine subSaharan African countries, was assessed for virulence diversity and genetic relatedness. The virulence spectrum was assessed by pathotype analysis with a panel of 43 rice genotypes consisting of differential lines carrying 24 blast resistance genes ( $R$-genes), contemporary African rice cultivars, and susceptible checks. The virulence spectrum among isolates ranged from 5 to $80 \%$. Five isolates were avirulent to the entire rice panel, while two isolates were virulent to $\sim 75 \%$ of the panel. Overall, cultivar $75-1-127$, the $P i 9$-gene donor, was resistant to all isolates $(100 \%)$, followed by four African rice cultivars (AR105, NERICA 15, 96\%; NERICA 4, 91\%; and

nucleotide polymorphisms derived from genotyping-by-sequencing and by vegetative compatibility tests. Phylogenetic analysis of SNPs of a subset of isolates $(n=78)$ revealed seven distinct clades that differed in virulence. Principal component analysis showed isolates from East Africa were genetically distinct from those from West Africa. Vegetative compatibility tests of a subset of isolates $(n=65)$ showed no common groups among countries. This study shows that blast disease could be controlled by pyramiding of $P i 9$ together with other promising $R$-genes into rice cultivars that are adapted to East and West African regions.
\end{abstract} F6-36, 90\%). Genetic relatedness of isolates was assessed by single

Rice (Oryza sativa L.) is the most important crop globally and is increasingly becoming a staple food for the majority of people in Africa (Sèrè et al. 2013). Despite its importance, production of rice in Africa is outstripped by demand, and the deficit is met through imports (Saito et al. 2013). To meet increasing demand and ensure food security in Africa, there is a fundamental need to increase the area under rice production in sub-Saharan Africa (Saito et al. 2013). Among the obstacles to increased rice production in sub-Saharan Africa is rice blast, a devastating fungal disease caused by the ascomycete fungus Magnaporthe oryzae (=Pyricularia oryzae) B. Couch (Sèrè et al. 2013). Much of the rice in Africa is produced in environments that favor blast disease, such as upland ecologies. Furthermore, most rice in sub-Saharan Africa is produced by smallscale farmers who cannot afford fungicides (Saito et al. 2013). Therefore, there is a need to adopt sustainable and farmer-friendly blast control methods, such as breeding for durable resistance in African rice varieties.

Magnaporthe oryzae is a hemibiotrophic pathogen with its origin in South East Asia (Saleh et al. 2014; Tharreau et al. 2009). The pathogen predominantly reproduces asexually but has a high potential for gene flow, spreading globally through trade of infected rice seed (McDonald and Linde 2002; Tharreau et al. 2009). The

Corresponding author: S. K. Mutiga;

E-mail addresses: mutiga@uark.edu and smutiga2008@gmail.com

First, second, and third authors contributed equally.

*The $\boldsymbol{e}$-Xtra logo stands for "electronic extra" and indicates that one supplementary figure and two supplementary tables are published online.

(c) 2017 The American Phytopathological Society
Additional keywords: resistance breeding, rice blast, virulence spectrum. first incidence of rice blast disease in Africa was reported in 1922 (Bidaux 1978) and the disease has since invaded all rice growing areas of sub-Saharan Africa (Sèrè et al. 2013). The pathogen infects and causes damage to rice plants at all stages of growth, leading to blast symptoms (elliptical gray-white lesions) that appear on aboveground organs, such as the leaves, collar, neck, node, panicle, and grain (Zhu et al. 2005). Higher crop damage is associated with neck blast symptoms and has been reported to cause heavy yield losses, of up to $100 \%$ in sub-Saharan Africa (Sèrè et al. 2013).

To retain parasitism and fitness, $M$. oryzae, as is the case with most plant pathogens, must acquire, evolve, or retain virulence across geographical locations. For example, pathogen populations with distinct virulence spectra (pathotypes) have been reported between isolates from Asia and those from Africa, but not between isolates of European and African origins. Differences in virulence across environments calls for a need to study the genetics and the virulence spectrum of the pathogen populations in order to identify the most effective resistance breeding strategy for target regions.

Blast resistance has been identified and is mainly controlled by one, or a few, major resistance genes, or $R$-genes (Miah et al. 2013; Valent and Chumley 1991). While several major resistance genes have been cloned and bred into rice varieties in different parts of the world, little progress has been made in sub-Saharan Africa (Miah et al. 2013). Furthermore, identified $R$-genes are effective only for certain regions and are frequently faced with risk of breakdown (McDonald and Linde 2002). Recognized regional differences in rice blast pathotypes imply a challenge to deployment of $R$-genes and an urgent need to understand pathogen population structure and variability. Breakdown of qualitative disease resistance is a rule, which is dependent on pathogen genetics and crop varietal deployment (de Wit 1992; McDonald and Linde 2002). The most economical strategy for overcoming the risk of resistance breakdown by 
intermediate pathogens, such as $M$. oryzae, is to pyramid $R$-genes into an adapted rice variety and/or to deploy multilines (McDonald and Linde 2002). In order to determine which $R$-genes could be pyramided to achieve durable blast control in a target region, it is imperative to characterize the virulence spectrum of the prevailing pathogen population. Prior to this study, the virulence spectrum of the African M. oryzae populations had not been wellcharacterized.

Characterization of the virulence spectrum (pathotyping) of a pathogen collection can be achieved using rice lines carrying known $R$-genes. Varieties with known blast $R$-gene disease can be evaluated under controlled conditions in a greenhouse, or under trapping nurseries in disease hotspot areas (Correa-Victoria and Zeigler 1993; Sèrè et al. 2007). Recently, the International Rice Research Institute (IRRI) developed a panel of rice differential lines carrying $24 R$-genes in a japonica background, Lijiangxintaunheigu (LTH; previously known to be universally susceptible to global blast pathogen collections) (Fukuta et al. 2004; Singh et al. 2015). These lines, later termed IRRI-bred blast-resistant lines (IRBLs), form a universal pathotype analysis panel and have previously been used to characterize the virulence spectrum of blast isolates from six West African countries. In the current study, the IRBLs and some African rice germplasm, including "New Rice for Africa" (NERICA) 2, 5, 12, and 15 cultivars were used to characterize the virulence of a diverse collection of African M. oryzae isolates from East and West Africa. Some of the African rice genotypes included in the pathotype analysis had been reported to be resistant to rice blast in three West African countries (Burkina Faso, Nigeria, and Mali) and were re-assessed on a wider pathogen population in the current study (Sèrè et al. 2008).

For successful host colonization in new environments, plant pathogens evolve adaptive virulence and fitness traits that enhance their ability to spread (McDonald and Linde 2002). Grouped as an intermediate pathogen in a risk model for overcoming host resistance, M. oryzae possesses high gene flow potential, which when combined with a (high/moderate rates of) mutation toward virulence, increases the pathogen's fitness in new environments (McDonald and Linde 2002; Tharreau et al. 2009). Furthermore, studies have shown that the pathogen can acquire additional fitness through sexual and parasexual recombination mechanisms under field conditions.

To gain insights into the evolutionary events, and how this relates to pathogen fitness, there is a growing need to analyze genetic relatedness and diversity. For fungi, the ability to form stable heterokaryons between two isolates is an important trait that enhances genetic diversity through parasexual recombination. Assessment of vegetative compatibility, based on complementation of nitrate nonutilizing mutants, has been useful in characterizing the genetic relatedness of most fungi, including $M$. oryzae (Correll et al. 1987, 2000; Leslie 1993). For example, over the last decades, distinct vegetative compatibility groups (VCGs) were identified and isolates belonging to specific groups were found to be more abundant in rice fields in the United States. A more recent tool for assessing genetic relatedness is genotyping-by-sequencing (GBS). Phylogenetic analysis of single nucleotide polymorphism (SNPs) derived from GBS has offered high genomic resolution and have been useful in fungal genomics and associated studies (Milgroom et al. 2014). In the current study, the genetic relatedness was assessed in a subset of the pathotyped African isolates of M. oryzae using SNPs derived from GBS and using vegetative compatibility tests $(n=65)$. The association between virulence and genetic relatedness, based on VCGs and SNPs, was assessed by comparing the virulence spectrum among the resulting major phylogenetic clusters.

In this study, the virulence spectrum of the African collection of the rice blast pathogen was assessed and utilized to determine appropriate breeding strategies to attain durable blast resistance in Africa. By using vegetative compatibility and whole-genome SNP methods, the genetic relatedness of isolates of M. oryzae from East and West Africa was characterized, and the association of genotype with virulence spectrum was established. Based on these observations, the blast disease resistance genes showing the greatest potential are highlighted and the appropriate breeding strategies are outlined for durable resistance to rice blast in East and West Africa.

\section{MATERIALS AND METHODS}

Description of the fungal population. The pathotyped M. oryzae population consisted of 122 isolates from nine African countries, including Benin, Burkina Faso, Mali, Ghana, Kenya, Nigeria, Tanzania, Togo, and Uganda. The collection consisted of a subset $(n=85)$ provided by D. Tharreau (Centre de Coopération Internationale en Recherche Agronomique pour le Développement, CIRAD, Montpellier, France), and had been selected to represent population clusters in a simple sequence repeats marker-based assessment of the diversity of a larger collection of $M$. oryzae from West African countries (D. Tharreau, unpublished data). Additional isolates $(n=37)$ were collected by collaborators in the rice blast project which was supported through the Sustainable Crop Production Research for International Development (SCPRID) initiative funded by Bill \& Melinda Gates Foundation through the Biotechnology and Biological Sciences Research Council (BBSRC) and Department for International Development (DFID) of the United Kingdom between 2012 and 2014. A random subset $(n=78)$ of the entire pathogen collection was selected for genotyping by GBS platform (Supplementary Table S1). To compare the African collection of isolates with world collections, eight isolates, hereinafter referred to as reference isolates, each from a major rice producing country outside the scope of the current collections (China, Egypt, Colombia, French Guyana, India, Philippines, United States, and South Korea) were included in the GBS panel. For vegetative compatibility analysis, only a subset $(n=65)$ whose single nitrate non-utilizing mutants (nits) complemented with the identified testers were reported.

Handling and preparation of fungal cultures. All fungal cultures were grown in rice bran agar (RBA) and stored on dry filter papers in vials at $-20^{\circ} \mathrm{C}$ prior to use in any of the studies. To produce the inoculum, the fungus was induced to sporulate by growing it on RBA under direct white light for 7 days. The spores were then washed from the media surface using $0.2 \%$ Tween 20 solution, counted using the hemocytometer, and normalized to a concentration of $2 \times 10^{5}$ conidia/ml. Mycelium for extraction of genomic DNA was grown from monoconidial spore stocks in complete nutrient broth (Jacobson and Gordon 1990) for 7 days with continuous light.

Description of the rice germplasm. The rice panel consisted of genotypes with known blast resistance genes $(n=24)$, susceptible checks (previously identified based on response to M. oryzae population from the United States and Asia), and several African lines (Table 1 ). Genotypes carrying the $24 R$-genes have a common genetic background of the Asian rice (japonica) cultivar called Lijiangxituanheigu, LTH. Seeds of the IRBLs and the background LTH cultivar were provided by IRRI and multiplied at the Dale Bumpers National Rice Research Center, Stuttgart, Arkansas. The cultivar 75-1-127 (Pi9 donor) was provided by the Wang Lab (The Ohio State University) within the research collaborative effort (Liu et al. 2002). The susceptible checks M204, UZ ROSZ 5, and Jumli dhan were available in the Correll Lab and had been previously used in pathotype analysis of isolates from the United States (Zhai 2012). Cultivars AR105 (Oryza glaberrima, commonly termed African rice), F6-36, and NERICA lines were provided by Dr. Ouédraogo (INERA-Burkina Faso) through a collaborative research effort (Linares 2002). The NERICA lines were developed by Africa Rice Center from crosses of $O$. glaberrima and $O$. sativa. This initiative was to enhance increased regional rice production by breeding for important traits into well-adapted African germplasm for cultivation under upland and lowland conditions. The interspecific NERICA cultivars had previously been screened for resistance to rice blast caused by $M$. oryzae isolates from West African 
countries. However, the reaction of the NERICA cultivars to $M$. oryzae isolates from other rice growing African countries had not been determined (Sèrè et al. 2007).

Characterization of the fungal population using the rice blast differential lines. Isolates were assessed for the reaction they caused when inoculated on the IRBLs and rice germplasm from Africa (Tables 2 and 3) under controlled temperature and humidity conditions, as described earlier, with some modifications. Briefly, the rice panel $(n=43)$ was grown on a rectangular vented nursery tray (part number HI2014032010, Edge Manufacturing Inc., Bluffton, IN) in a greenhouse (temperature range of 19 to $26^{\circ} \mathrm{C}$ ) for 21 days before being inoculated with individual isolates. Each rice genotype was represented by a hill of 10 to 15 seedlings, which were sown on a tray containing 2:1 potting mixture of sandy soil and Sunshine LC1 (Sungro Horticulture Ltd., Agawam, MA). Seedlings were inoculated with fungal conidial suspension at a concentration of $2 \times 10^{5} \mathrm{conidia} / \mathrm{ml}$ using an atomized compressed sprayer. Inoculated seedlings were incubated in a dew chamber (relative humidity, $\approx 100 \%$; temperature, 21 to $23^{\circ} \mathrm{C}$ ) for $24 \mathrm{~h}$ prior to transferring them back to the greenhouse. Foliar blast was evaluated at 7 days after inoculation on a 0 to 9 visual score scale, where $0=$ no visible damage, 1 to 3 varying degrees of hypersensitive reaction, and 4 to 9 varying degrees of blast severity. Test results with contrasting disease reactions were identified in the first two tests and the rice genotype-isolate sets were retested in subsequent experiments.

TABLE 2. Distribution of the isolates of Magnaporthe oryzae and a likelihood ratio test for differences in virulence versus avirulence of isolates across nine African countries ${ }^{\mathrm{z}}$

\begin{tabular}{|c|c|c|c|c|c|c|}
\hline \multirow[b]{2}{*}{ Country } & \multirow{2}{*}{$\begin{array}{l}\text { Isolates } \\
\quad(n)\end{array}$} & \multirow{2}{*}{$\begin{array}{l}\text { Odds ratio } \pm \\
\text { standard error }\end{array}$} & \multirow[b]{2}{*}{$\chi^{2}$} & \multirow[b]{2}{*}{$P$ value } & \multicolumn{2}{|c|}{$\begin{array}{c}\text { Confidence } \\
\text { interval }(95 \%)\end{array}$} \\
\hline & & & & & Lower & Upper \\
\hline Burkina Faso & 15 & $0.63 \pm 1.09$ & 31.38 & $<0.0001$ & 0.54 & 0.74 \\
\hline Uganda & 5 & $0.71 \pm 1.14$ & 6.68 & 0.0097 & 0.55 & 0.92 \\
\hline Kenya & 13 & $0.95 \pm 1.09$ & 0.35 & 0.5527 & 0.80 & 1.12 \\
\hline Nigeria & 33 & $0.98 \pm 1.06$ & 0.08 & 0.7804 & 0.87 & 1.11 \\
\hline Mali & 3 & $1.03 \pm 1.18$ & 0.03 & 0.8565 & 0.74 & 1.43 \\
\hline Benin & 19 & $1.05 \pm 1.08$ & 0.41 & 0.5199 & 0.91 & 1.22 \\
\hline Tanzania & 23 & $1.19 \pm 1.07$ & 6.22 & 0.0126 & 1.04 & 1.37 \\
\hline Togo & 8 & $1.24 \pm 1.11$ & 3.93 & 0.0474 & 1.00 & 1.52 \\
\hline \multicolumn{7}{|l|}{ Ghana } \\
\hline (reference) & 3 & & & & & \\
\hline
\end{tabular}

$\overline{\mathrm{z}}$ Disease reactions are based on reactions of rice genotypes $(n=42)$ against African isolates of M. oryzae $(n=122)$.

TABLE 1. Description of the rice germplasm used in characterization of the isolates of Magnaporthe oryzae from Africa

\begin{tabular}{|c|c|c|c|c|}
\hline Rice genotype & Description & Target $R$-gene ${ }^{\mathrm{z}}$ & $\begin{array}{l}\text { Donor line/pedigree } \\
\text { for NERICA }\end{array}$ & Reference \\
\hline IRBL11-ZH & Differential line & $\operatorname{Pi11}(t)$ & Zhaiyeqing & Fukuta et al. 2004 \\
\hline IRBL12-M & Differential line & $\operatorname{Pi12}(t)$ & RIL10 (Moroberekan) & \\
\hline IRBL19-A & Differential line & Pil9 & Aichi Asahi & \\
\hline IRBL1-CL & Differential line & Pil & C101LAC & \\
\hline IRBL20-IR24 & Differential line & $\operatorname{Pi2O}(t)$ & IR 24 & \\
\hline IRBL3-CP4 & Differential line & Pi3 & C104PKT & \\
\hline IRBL5-M & Differential line & $\operatorname{Pi5}(t)$ & RIL249 (Moroberekan) & \\
\hline IRBL7-M & Differential line & $\operatorname{Pi}(t)$ & RIL29 (Moroberekan) & \\
\hline IRBL9-W & Differential line & $\operatorname{Pi9}$ & WHD-1S-75-1-127 & \\
\hline IRBLA-a & Differential line & Pia & Aichi Asahi & \\
\hline IRBLB-B & Differential line & $P i b$ & BL 1 & \\
\hline IRBLI-F5 & Differential line & Pii & Fujisaka 5 & \\
\hline IRBLKH-K3 & Differential line & $P i k-h$ & K 3 & \\
\hline IRBLK-KA & Differential line & $P i k$ & Kanto 51 & \\
\hline IRBLKM TS & Differential line & Pik-m & Tsuyuake & \\
\hline IRBLKP-K60 & Differential line & Pik-p & K 60 & \\
\hline IRBLKS-F5 & Differential line & Pik-s & Fujisaka 5 & \\
\hline IRBLKS-S & Differential line & $P i k-s$ & Shin 2 & \\
\hline IRBLSH-B & Differential line & Pish & BL 1 & \\
\hline IRBLSH-S & Differential line & Pish & Shin 2 & \\
\hline IRBLTA 2-PI & Differential line & Pita2 & Pi No. 4 & \\
\hline IRBLTA 2-RE & Differential line & Pita2 & Reiho & \\
\hline IRBLTA CP 1 & Differential line & Pita & C101PKT & \\
\hline IRBLTA CT2 & Differential line & Pita & C105TTP2L9 & \\
\hline IRBLT-K59 & Differential line & Pit & K 59 & \\
\hline IRBLZ5-CA(R) & Differential line & $P i z-5$ & C101A51 & \\
\hline IRBLZ5-CA & Differential line & $P i z-5$ & C101A51 & \\
\hline IRBLZ-FU & Differential line & $\mathrm{Piz}$ & Fukunishiki & \\
\hline IRBLZT-T & Differential line & Piz-t & Toride 1 & \\
\hline IRBTP16211/Lijiangxituanheigu (LTH) & Japonica variety & Pik-1 & NA & Singh et al. 2015 \\
\hline $75-1-127$ & Pi9 donor line & $\operatorname{Pi9}$ & NA & Liu et al. 2002 \\
\hline AR105 & Oryza glaberrima & - & NA & Linares 2002 \\
\hline NERICA 12 & African upland & - & WAB880-1-38-20-17-P1-HB & Sèrè et al. 2007 \\
\hline NERICA 15 & African upland & - & WAB881-10-37-18-3-P1-HB & \\
\hline NERICA 2 & African upland & - & WAB450-11-1-P31-1-HB & \\
\hline NERICA 4 & African upland & - & WAB450-I-B-P-91-HB & \\
\hline NERICA 5 & African upland & - & WAB450-11-1-1-P31-HB & \\
\hline FKR62N & African lowland & - & WAS122-IDSA-1-WAS-6-1 & \\
\hline TS2 & African intraspecific & - & NA & http://www.ars-grin.gov/npgs/ \\
\hline F6-36 & African intraspecific & - & NA & \\
\hline Jumli dhan & Susceptible check & - & NA & \\
\hline UZ R0SZ 5 & Susceptible check & - & NA & \\
\hline M204 & Susceptible check & - & M-201/M7/3/M7//ESD7-3/Kokuhorose & Zhai 2012 \\
\hline
\end{tabular}

z A hyphen in the target $R$-gene column means that the resistance gene(s) have not been identified. 
Fungal DNA extraction and preparation for genotypingby-sequencing. The random subset $(n=78)$ and the eight reference isolates used for assessment of genetic relatedness using SNPs were genotyped using a GBS platform at the Genomic Diversity Facility, Cornell University. Genomic DNA for GBS was extracted from flash frozen mycelium using Qiagen's DNeasy Plant mini kit, per manufacturer's protocol (Qiagen, Valencia, CA). DNA was eluted in $40 \mu \mathrm{l}$ of $\mathrm{AE}$ buffer and stored at $-20^{\circ} \mathrm{C}$. Final concentrations were estimated using NanoDrop2000c UV spectrophotometer (Thermo Fisher Scientific Corp., Waltham, MA) and were normalized to $50 \mathrm{ng} / \mu \mathrm{l}$. The quality of the DNA was confirmed through test digestions using HindIII prior to shipping the samples to Cornell University.

Construction and analysis of GBS library. GBS libraries were constructed with the enzyme ApeK1 using previously described protocols. The libraries were sequenced in a single lane by Illumina HiSeq2000 100-bp single-end method (Illumina, Inc., San Diego, CA). Data were preprocessed and aligned to M. oryzae Guy11 genome de novo contigs, the reference genome, using the GBS analysis pipeline in TASSEL Version: 3.0.166 and BWA version 0.7.8r455 (Glaubitz et al. 2014; Li and Durbin, 2009). SNPs from the genotyped collection of 86 isolates were obtained in both HapMap and VCF formats. Because the VCF format retains the information on the depth of coverage for each allele, the VCF files were used for further analysis. The likelihood scores for each genotype were calculated using formula 3.8 and the most likely genotype was assigned. SNPs were filtered further using VCFtools v0.1.12 as follows: (i) Sites with less than $80 \%$ information were removed (-max-missing 0.8), (ii) minor allele frequency (MAF) was $>1 \%$ (-maf 0.01), (iii) minimum depth of reads was set to 10 (-minDP 10 ), and (iv) minimum genotype quality was set to 98 (-minGQ 98).

Assessment of fungal vegetative compatibility. The analysis of VCG was performed using a previously described procedure. Briefly, nit testers (unique mutants with the ability to form a heterokaryon with multiple other individual mutants) were recovered from two to three isolates per country. The nit mutants are characterized by thin mycelial spread on the minimal media. To recover nit testers, between 20 to 30 nits each were generated by growing isolates on a minimal media modified with $5 \%$ potassium chlorate. The nit mutants were paired in a plate of 10 individual nits to identify the unique mutant which formed a heterokaryon (complementation of the mutation which is characterized by a vigorous mycelial growth formed at the junction of the spread of the two mutants on the minimal media) with the majority of the other mutants within the plate. The testers were subcultured, grown on rice bran agar and stored on filter papers as described earlier. To test for complementation of the rest of the fungal population, a single nit mutant was generated for each of the isolates. The single nit mutants were thereafter paired with the testers within and among countries. Data were collected on the ability of the isolates to form a heterokaryon with the tester within a duration of 21 days. Isolates were assigned to a VCG based on the identity of the testers with which they successfully complemented.

Statistical analysis. Depending on the factors being compared, raw disease reaction scores were either used as response variables in a standard least squares regression or the mean disease reaction scores from a pair of isolate-rice genotype were binary coded and used as responses in a binomial logistic regression in JMP Pro ver. 12 (SAS Institute Inc., Cary, NC). A standard least squares regression model was used to compute the least squares of means of disease reaction scores for the African rice cultivars and the susceptible checks, and for the pooled scores of the isolates within clades derived from the SNP phylogeny. Means were compared using Tukey's honest significant difference test at a significance level of 0.05 . Disease reactions were coded as follows: 0 to 3 (resistance) was coded as 0 , while 4 to 9 (susceptible) was coded as 1 . The proportions of isolates which were virulent on the IRBLs were compared using analysis of means for proportions (ANOMP) in JMP Pro ver. 12 (SAS Institute Inc.). Virulence among VCGs and countries was conducted using likelihood ratio tests in a binomial regression model. Filtered SNPS were used for phylogenetic and principal component analysis(es) (PCA) in TASSEL v5.2.1.6 as follows. A pairwise distance matrix between individuals/taxa was calculated and an unrooted neighbor joining tree was constructed. PCA was performed and the values of the first three components were exported to $\mathrm{R}$ for plotting using the plot() and P3D functions (R Core Team 2015).

\section{RESULTS}

Descriptive statistics of isolates. The fungal collections characterized in this study consisted of isolates collected from diseased rice plants in the nine African countries. From the pathotyped collection $(n=122)$, West African countries constituted the largest proportion of isolates $(66 \%, n=81)$ compared with East Africa (34\%, $n=41)$. Countries with the highest and lowest sample sizes were as follows. Nigeria had the largest sample size $(n=33 ; 27 \%)$, followed by Tanzania $(n=23 ; 19 \%)$ and Benin $(n=19 ; 16 \%)$, while Mali and Ghana had the least number of isolates with three samples each (Table 2). Out of the subset of African isolates $(n=78)$ that were used in genetic characterization using GBS-derived SNPs, $64 \%$ (50/78) were from West Africa while 36\% (28/78) were from East Africa. Of the isolates $(n=65)$ used in the vegetative compatibility characterization, 60\% (39/65) were from West Africa while $40 \%$ (26/65) were from East Africa.

Virulence spectrum of $M$. oryzae and resistance spectrum of the rice panel. Based on likelihood ratio tests, significant

TABLE 3. Pairwise comparison of countries for the likelihood of occurrence of virulence based on inoculation of a panel of rice $(n=42)$ with isolates of Magnaporthe oryzae $(n=122)$ from nine African countries

\begin{tabular}{|c|c|c|c|c|c|c|}
\hline \multicolumn{3}{|c|}{ Pairwise comparison of countries } & \multirow{3}{*}{$\begin{array}{l}\text { Odds } \\
\text { ratio }\end{array}$} & \multirow[b]{3}{*}{$P$ value } & \multirow{2}{*}{\multicolumn{2}{|c|}{$\begin{array}{c}\text { Confidence } \\
\text { interval }(95 \%)\end{array}$}} \\
\hline \multirow{2}{*}{$\begin{array}{l}\text { Region of } \\
\text { country } 1\end{array}$} & \multirow[b]{2}{*}{ Country 1} & \multirow[b]{2}{*}{ Country 2} & & & & \\
\hline & & & & & Lower & Upper \\
\hline East Africa & Kenya & Nigeria & 0.97 & 0.7455 & 0.79 & 1.18 \\
\hline East Africa & Kenya & Burkina Faso & 1.51 & 0.0005 & 1.20 & 1.90 \\
\hline East Africa & Kenya & Benin & 0.91 & 0.3777 & 0.73 & 1.13 \\
\hline East Africa & Kenya & Togo & 0.77 & 0.0635 & 0.58 & 1.01 \\
\hline East Africa & Kenya & Mali & 0.92 & 0.6893 & 0.62 & 1.37 \\
\hline East Africa & Kenya & Ghana & 0.64 & 0.0273 & 0.43 & 0.95 \\
\hline East Africa & Tanzania & Uganda & 1.67 & 0.001 & 1.23 & 2.26 \\
\hline East Africa & Tanzania & Kenya & 1.25 & 0.0364 & 1.01 & 1.55 \\
\hline East Africa & Tanzania & Nigeria & 1.21 & 0.025 & 1.02 & 1.44 \\
\hline East Africa & Tanzania & Burkina Faso & 1.89 & $<0.0001$ & 1.54 & 2.33 \\
\hline East Africa & Tanzania & Benin & 1.14 & 0.1967 & 0.94 & 1.38 \\
\hline East Africa & Tanzania & Togo & 0.97 & 0.7854 & 0.75 & 1.25 \\
\hline East Africa & Tanzania & Mali & 1.16 & 0.4529 & 0.79 & 1.69 \\
\hline East Africa & Uganda & Kenya & 0.75 & 0.0827 & 0.54 & 1.04 \\
\hline East Africa & Uganda & Nigeria & 0.73 & 0.0348 & 0.54 & 0.98 \\
\hline East Africa & Uganda & Burkina Faso & 1.13 & 0.4372 & 0.83 & 1.56 \\
\hline East Africa & Uganda & Benin & 0.68 & 0.015 & 0.50 & 0.93 \\
\hline East Africa & Uganda & Togo & 0.58 & 0.0023 & 0.41 & 0.82 \\
\hline East Africa & Uganda & Mali & 0.69 & 0.112 & 0.44 & 1.09 \\
\hline East Africa & Uganda & Ghana & 0.48 & 0.0015 & 0.30 & 0.76 \\
\hline West Africa & Benin & Togo & 0.85 & 0.2243 & 0.65 & 1.10 \\
\hline West Africa & Benin & Mali & 1.02 & 0.9245 & 0.69 & 1.50 \\
\hline West Africa & Benin & Ghana & 0.70 & 0.0776 & 0.48 & 1.04 \\
\hline West Africa & Burkina Faso & Benin & 0.60 & $<0.0001$ & 0.48 & 0.74 \\
\hline West Africa & Burkina Faso & Togo & 0.51 & $<0.0001$ & 0.39 & 0.67 \\
\hline West Africa & Burkina Faso & Mali & 0.61 & 0.0139 & 0.41 & 0.90 \\
\hline West Africa & Burkina Faso & Ghana & 0.42 & $<0.0001$ & 0.28 & 0.63 \\
\hline West Africa & Mali & Ghana & 0.69 & 0.1544 & 0.41 & 1.15 \\
\hline West Africa & Nigeria & Burkina Faso & 1.56 & $<0.0001$ & 1.28 & 1.89 \\
\hline West Africa & Nigeria & Benin & 0.94 & 0.4702 & 0.78 & 1.12 \\
\hline West Africa & Nigeria & Togo & 0.80 & 0.0674 & 0.62 & 1.02 \\
\hline West Africa & Nigeria & Mali & 0.95 & 0.8033 & 0.66 & 1.39 \\
\hline West Africa & Nigeria & Ghana & 0.66 & 0.0309 & 0.45 & 0.96 \\
\hline West Africa & Tanzania & Ghana & 0.80 & 0.2535 & 0.54 & 1.17 \\
\hline West Africa & Togo & Mali & 1.20 & 0.3977 & 0.79 & 1.82 \\
\hline West Africa & Togo & Ghana & 0.83 & 0.3819 & 0.54 & 1.27 \\
\hline
\end{tabular}


differences in virulence were found among isolates from different African countries $\left(\chi^{2}=54.4[\mathrm{df}=8, n=4,924] P<0.0001\right)$. Generally, the spectrum of virulence ranged from $0 \%$ (in five Nigerian isolates) to $80 \%$ (in a Ghanaian isolate). The odds of virulence were least in isolates from Uganda and Burkina Faso, and were highest in isolates from Ghana, Togo, and Tanzania (Table 2). Although Ghana had the highest odds of virulence, the country was represented by a few isolates. No significant differences $(P>0.05)$ were observed in the likelihood of virulence among isolates from Benin, Kenya, Nigeria, and Mali (Table 3). By splitting the pathogen collections into East and West Africa, the virulence spectrum of isolates was assessed on a regional basis (Figs. 1, 2, and 3). Isolates from East Africa comprised of collections from Kenya, Uganda, and Tanzania, while West African isolates were from Benin, Burkina Faso, Ghana, Mali, Nigeria, and Togo. Regression and cluster analysis were used to assess the relationship between the region of origin of an isolate and their virulence. When the origins of the isolates were grouped into two geographical locations, East and West Africa, the likelihood of virulence was marginally similar between the two regions (odds ratio $=0.95, P=0.09$ ). However, the disease reaction patterns were different for isolates from the two regions (Figs. 2 and 3).

Because the complete avirulence of the five Nigerian isolates on all rice genotypes was unexpected, two of them (NG0104 and NG0110) were further characterized through pathogenicity tests, growth patterns (including their ability to form appressoria), and whole-genome sequencing. For pathogenicity tests, isolates were first inoculated onto wounded rice leaves and were found not to cause infection. They were also grown on hydrophobic surfaces and leaf sheath preparations and were found to be unable to form appressoria. The isolates formed structures similar to hyphopodia instead of normal infection structures (appressoria and invasive hyphae). Whole-genome sequence analysis did not show any major differences in reported genes involved in appressorium formation compared with pathogenic isolates (V. M. Were, unpublished data).
The responses of African rice germplasm and susceptible checks, previously identified in other regions, to the African blast pathogen population were assessed based on mean disease scores (Table 4). Susceptible genotypes with an overall average disease score $\geq 4$ (on a scale of 0 to 9) included Jumli dhan, Lijiangxituanheigu (LTH), and M204 (Table 4). The NERICA varieties included in this study showed an overall resistance to the blast collections from across the nine countries, with aggregate disease scores ranging from 1.5 to 2.7. The disease scores of the NERICAs 4, 5, and 12 were statistically similar to that of TS2 (West African rice cultivar) $(P>$ 0.05). The most resistant African cultivars were AR105 and F6-36, with disease mean scores ranging from 0.4 to 1.1 , respectively, but these cultivars were tested on only a subset of isolates (AR105, $n=46$; F6-36, $n=81$ ), compared with most other lines, which were inoculated with 122 isolates (Table 4).

Based on analysis of the means for proportions method, the entire pathotyping panel conferred resistance to a range of isolates between 2.5 to $100 \%$, with a mean proportion of $51 \%$. The African cultivars and the interspecific varieties were resistant to isolates ranging from 69 to $96 \%$ (Fig. 1). African lines that conferred resistance to most isolates were AR105 (overall, 96\%; East Africa, 96\%; West Africa, 91\%) and F6-36 (overall, 90\%; East Africa, 97\%; West Africa, 87\%). Across the two regions, NERICA lines were resistant to the following proportions of isolates: East Africa (76 to 91\%) and West Africa (66 to 99\%). For East Africa, the resistance of the NERICA lines in the descending order was as follows: NERICA $15=$ NERICA $5=$ NERICA $4>$ NERICA $2>$ NERICA 12 . For West Africa, the resistance of the NERICA lines in descending order was as follows: NERICA $15>$ NERICA $4>$ NERICA $2>$ NERICA $5>$ NERICA 12.

A comparison of the response of rice differential lines carrying known rice blast resistance genes showed that line 75-1-127 (Pi9 donor) conferred resistance against $100 \%$ of the entire collection of African isolates, followed by IRBL9-W (Pi9) and IRBLTA 2-RE (Pita2) both of which were resistant to $86 \%$ of the
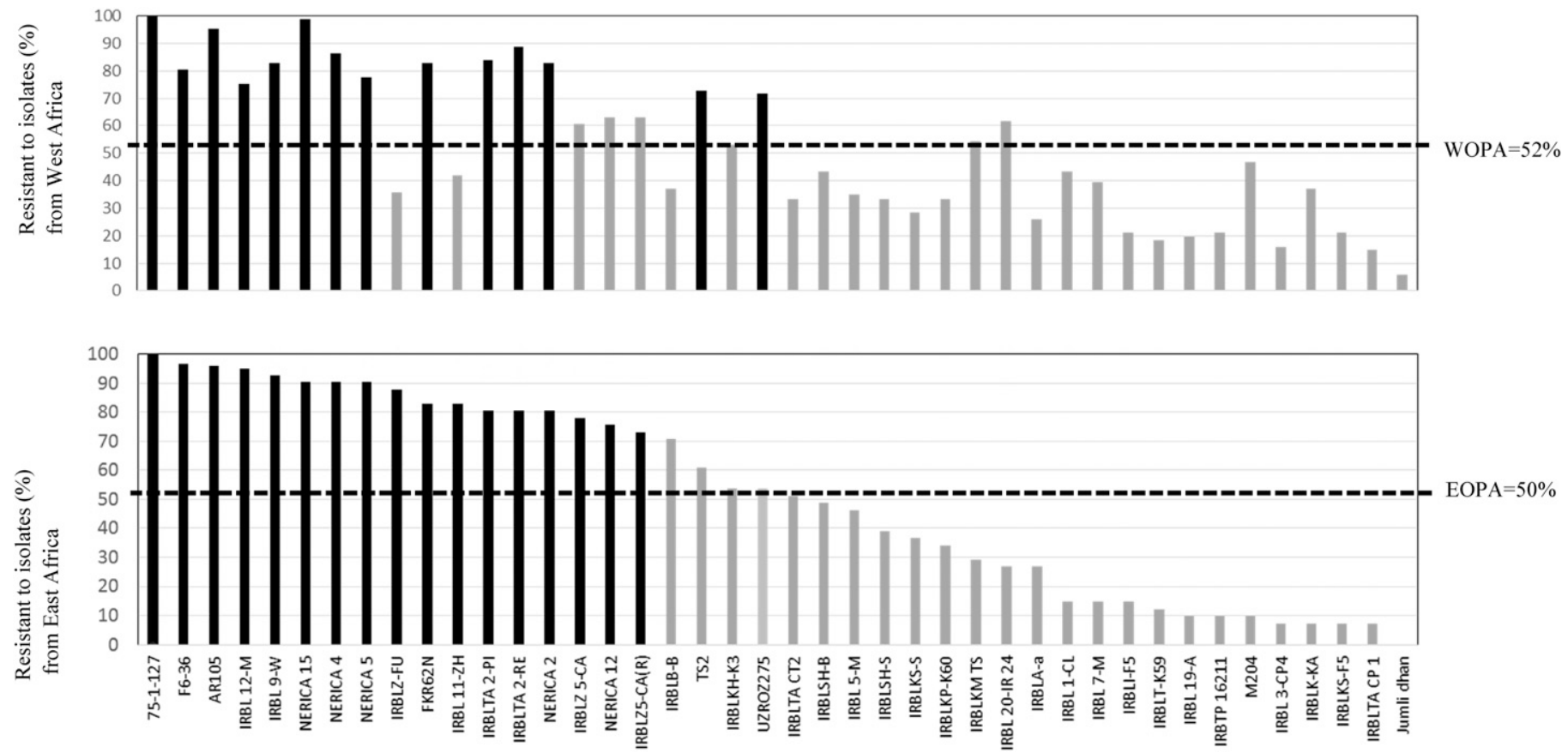

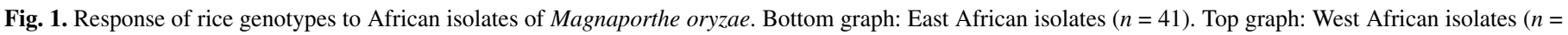

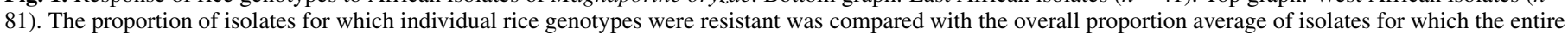

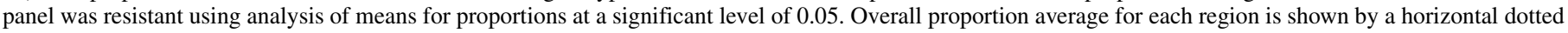

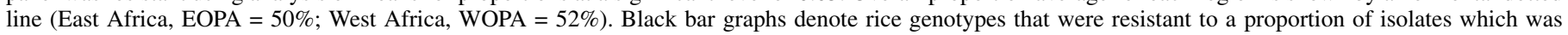

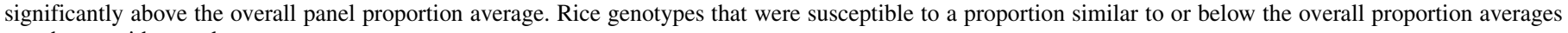
are shown with gray bars. 
isolates. Lines that conferred resistance to a proportion of isolates below (2.5 to $35 \%)$ of the population mean were those carrying Pita, Pi3, Pii, Pi19, Pit, Pik-S, Pik, Pik-p, Pi-1, Pish, Pia, and Pi7 $(t)$. Although the overall disease reactions for IRBLZT-T, a monogenic line presumed to contain Piz-t $R$-gene, were included in the summary of the rice panel response patterns (Figs. 2 and 3), a separate complementary study involving PCR tests for the corresponding avirulence gene (avr-Piz-t) in a subset of isolates showed that the $R$-gene may not have been present and/or effective (Supplementary Table S2) (V. M. Were, unpublished data). The line was therefore excluded from the subsequent overall analysis.

For the collection of isolates from East Africa, the pathotyping panel conferred resistance to isolates ranging from 0 to $100 \%$, with a mean of $50 \%$. The order of lines which conferred resistance to most isolates was as follows: 75-1-127 (Pi9 donor) > IRBL12-M (Pi12 $(t))$ $>$ IRBL9-W (Pi9 monogenic line) $>$ IRBLZ-FU $(P i z)>$ IRBL11-ZH $($ Pill $)>$ IRBLTA 2-PI $=$ IRBLTA2-RE $($ Pita2) $>$ IRBLZ-CA

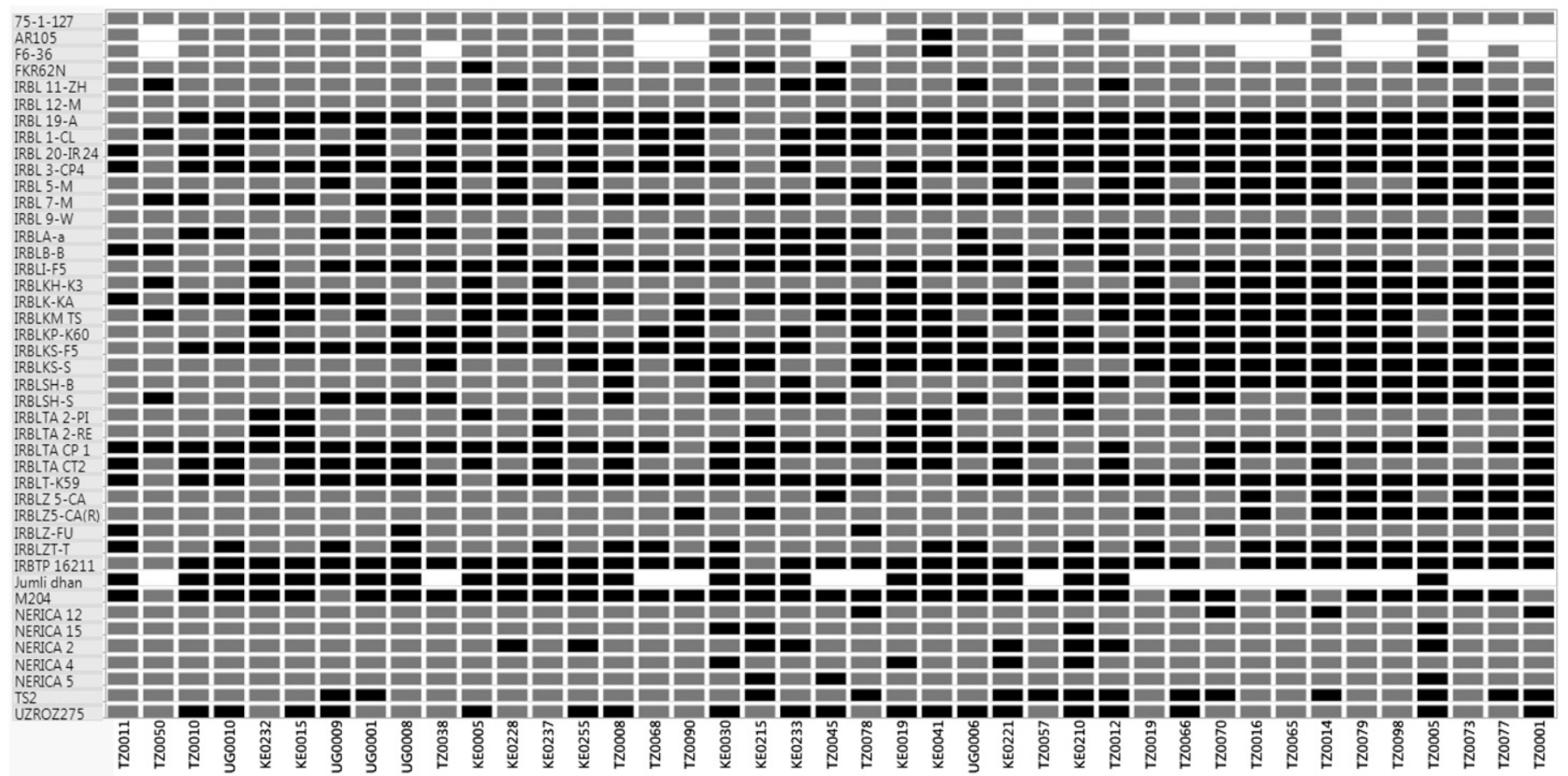

Fig. 2. Disease reactions of differential rice lines to isolates $(n=41)$ of Magnaporthe oryzae from East Africa. Rice genotypes in the $\mathrm{y}$ axis, and isolate names in the $\mathrm{x}$ axis. Black and gray indicate virulence and avirulence, respectively. White blank spaces indicate that pathotyping was not conducted using the rice genotype-isolate set.

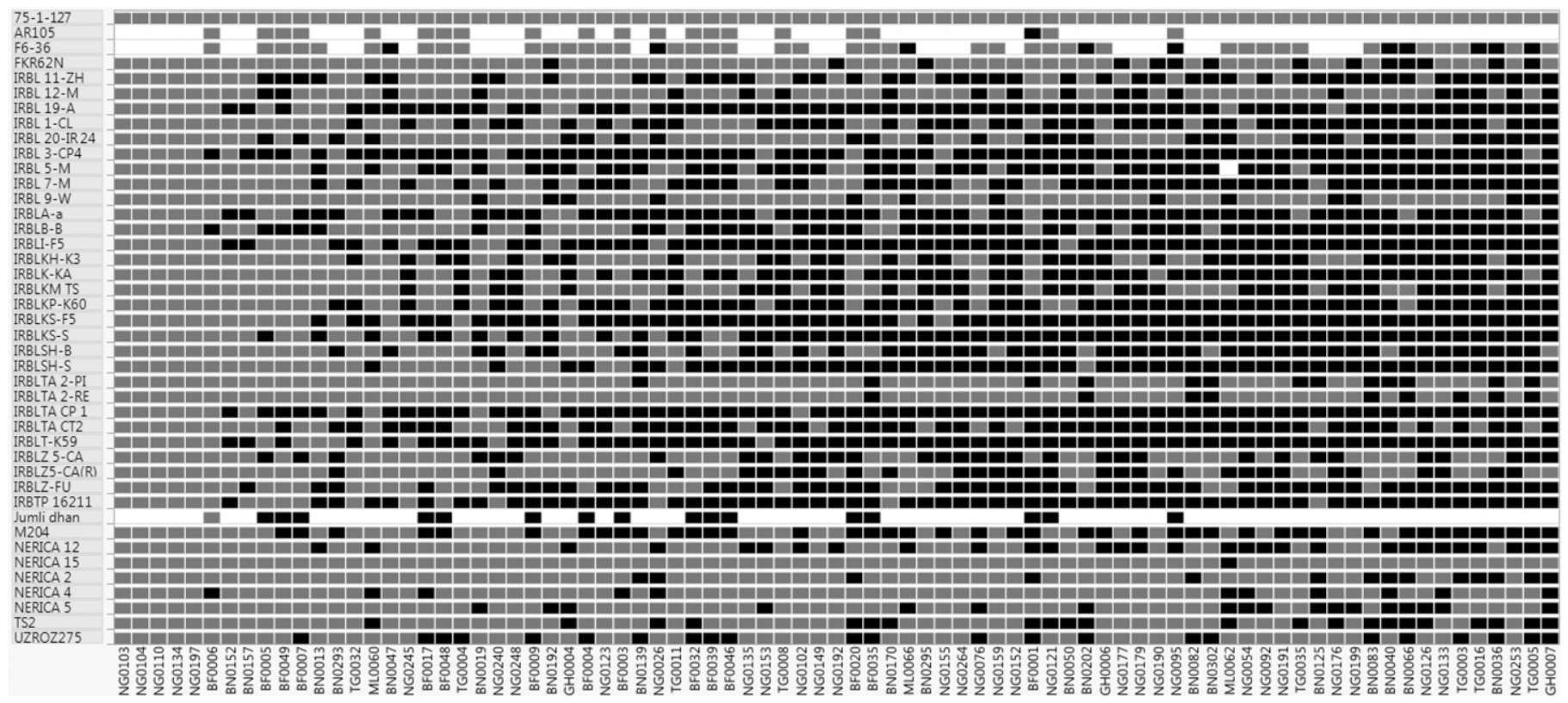

Fig. 3. Disease reactions of differential rice lines to isolates $(n=81)$ of Magnaporthe oryzae from West Africa. Rice genotypes in the y axis, and isolate names in the $\mathrm{x}$ axis. Black and gray indicate virulence and avirulence, respectively. White blank spaces indicate that pathotyping was not conducted using the rice genotypeisolate set. 
( $\mathrm{R}$, Piz-5). Lines which conferred resistance to a proportion (0 to $24 \%$ ) of isolates below the population mean included those carrying Pi3, Pita, Pi19, Pik, Pii, Pik-S, Pit, Pi7(t), and Pil (Fig. 1). The mean proportion of the rest of the lines did not differ significantly from that of the whole pathotyping panel (Fig. 1). For the collection of isolates from West Africa, the pathotyping panel conferred resistance to isolates ranging from 6 to $100 \%$, with a mean of $52 \%$. The order of lines (genotypes) that conferred resistance to most isolates was as follows: 75-1-127 > Pita2 > IRBL9-W > IRBL12-M (Pi12-t). Lines which conferred resistance to a proportion (15 to $35 \%$ ) of isolates below the population mean included those carrying Pita, Pi3, Pii, Pish, Pit, Pik- S, Pik-p, Pia, $P i i$, and Pi19 (Fig. 1). The mean proportion of the rest of the lines did not differ significantly $(P>0.05)$ from that of the whole pathotyping panel (Fig. 1).

TABLE 4. Comparison of mean disease score for African rice and selected checks in pathotype analysis of Magnaporthe oryzae isolates from Africa

\begin{tabular}{|c|c|c|c|c|}
\hline \multirow[b]{3}{*}{ Cultivar } & \multirow[b]{3}{*}{ Isolates $(n)$} & \multicolumn{3}{|c|}{ Disease score (0-9 scale) } \\
\hline & & \multirow[b]{2}{*}{$\mathrm{LSM} \pm \mathrm{SE}^{\mathrm{z}}$} & \multicolumn{2}{|c|}{$\begin{array}{l}95 \% \text { Confidence } \\
\text { interval }\end{array}$} \\
\hline & & & Lower & Upper \\
\hline Jumli dhan & 40 & $5.7 \pm 0.2 \mathrm{a}$ & 5.2 & 6.1 \\
\hline IRBTP 16211 & 122 & $4.6 \pm 0.1 b$ & 4.3 & 4.8 \\
\hline M204 & 122 & $3.9 \pm 0.1 \mathrm{c}$ & 3.7 & 4.2 \\
\hline UZROZ275 & 122 & $2.8 \pm 0.1 \mathrm{~d}$ & 2.6 & 3.0 \\
\hline NERICA 12 & 122 & $2.7 \pm 0.1 \mathrm{~d}$ & 2.5 & 2.9 \\
\hline $\mathrm{TS} 2$ & 122 & $2.6 \pm 0.1 \mathrm{~d}$ & 2.3 & 2.8 \\
\hline NERICA 4 & 122 & $2.4 \pm 0.1 \mathrm{de}$ & 2.2 & 2.6 \\
\hline NERICA 5 & 122 & $2.3 \pm 0.1 \mathrm{de}$ & 2.1 & 2.5 \\
\hline NERICA 2 & 122 & $1.9 \pm 0.1 \mathrm{ef}$ & 1.7 & 2.1 \\
\hline FKR62N & 122 & $1.9 \pm 0.1 \mathrm{ef}$ & 1.6 & 2.1 \\
\hline NERICA 15 & 122 & $1.5 \pm 0.1 \mathrm{fg}$ & 1.3 & 1.7 \\
\hline F6-36 & 81 & $1.1 \pm 0.2 \mathrm{gh}$ & 0.7 & 1.4 \\
\hline AR105 & 46 & $0.4 \pm 0.2 \mathrm{~h}$ & 0.0 & 0.8 \\
\hline
\end{tabular}

${ }^{\mathrm{z}}$ Least square mean \pm standard error of disease scores. Means were separated and compared using Tukey's honest significant difference test at $\alpha=0.05$. Means followed by the same letter do not differ significantly.
The ANOMP method used in the current study relies on average disease scores to infer the binary values of avirulence $(<4)$ or virulence $(>4)$. A pairwise comparison of the binary values with those obtained based on maximum disease scores showed a strong correlation $(r=0.72, P<0.0001)$. An assessment of the response of the most resistant rice genotype, 75-1-127, based on the maximum disease scores showed that it was susceptible to six isolates (Supplementary Fig. S1). Similarly, the resistance spectrum of IRBL9-W was reduced from the overall 87 to $68 \%$ when maximum disease scores were used to infer the binary reactions.

Genetic relatedness of $M$. oryzae based on SNPs. Using GBS, 9,710 polymorphic sites were identified from the 86 isolates analyzed. A phylogenetic analysis using the unrooted NeighborJoining method, based on a pair-wise distance matrix of the 86 isolates (East Africa, 28; West Africa, 50; and reference, 8; respectively) showed distinct segregation of East and West African isolates into different clades compared with the reference group (Fig. 4A). Most of the West Africa isolates were found to be clustered in five clades $(1,2,3,5$, and 6$)$, while the remaining isolates belonging to East Africa predominantly clustered within clades 4 and 7 . Interestingly, clade 1 and clade 2 also showed the presence of certain East African isolates (one and two isolates, respectively) suggesting either as the source of the isolate/outbreak. Further, a single isolate from West Africa (isolate TG0003) segregated from the rest of the major clades as an independent subclade (Fig. 4A). Clustering of the eight reference isolates (49D, CHNOS_6, EG324, FC10, GUY11, IN24, P06_06, and KJ201) in the phylogenetic clades was assumed to depict the evolutionary relatedness with the African isolates. For example, in clade 1, 30/48 isolates from West Africa clustered with the Colombian isolate FC-10, while in clade 4, 27/40 isolates from East Africa clustered with the U.S. isolate 49D (Fig. 4A).

To identify patterns of population structure within the East and West African isolates, PCA was performed. As shown in Figure 4B, the 3D PCA plot of the variant data from GBS showed segregation among the East and West African isolates into seven groups similar to their representation in a pair-wise distance matrix (Fig. 4), suggesting a close phylogenetic relationship of isolates within the different sub-Saharan African countries. Furthermore, examination of the PCA scores plot of PC1 versus PC2 showed a clear separation
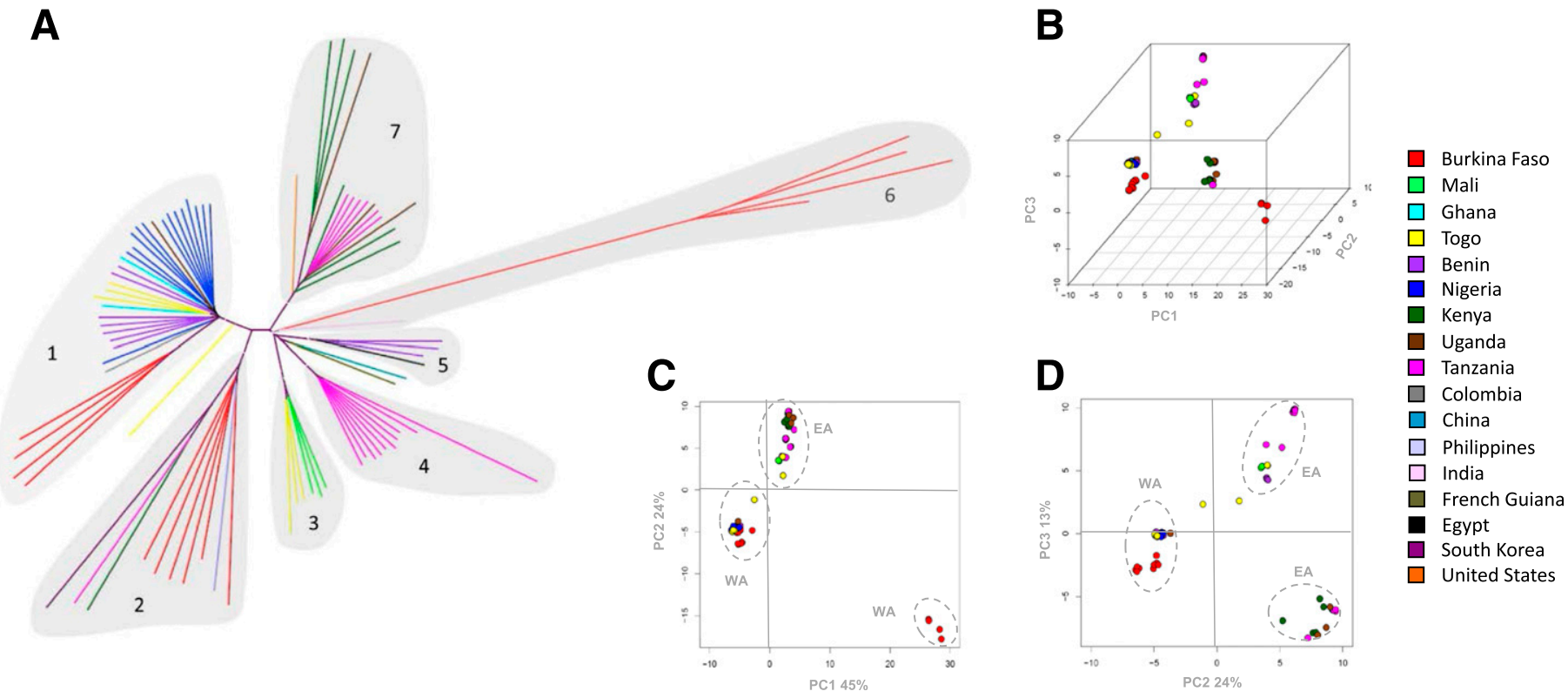

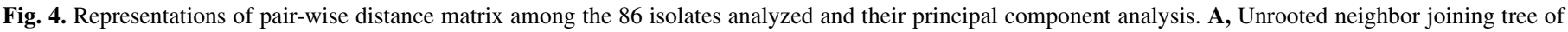

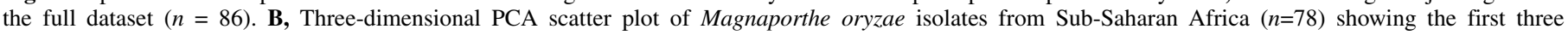

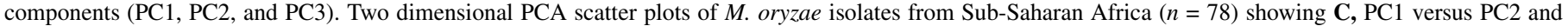
D, PC2 versus PC3. EA, East Africa; WA, West Africa. Isolates are color-coded by country and represented by lines and filled circles. 
of East and West African isolates. The separation was mainly due to PC1, which accounted for $45 \%$ of the variability, while PC2 accounted for $24 \%$ indicating that the differences among isolates were mainly from West Africa, especially Burkina Faso. Similarly, the PCA scores plot of PC2 versus PC3, mainly showed the separation of East African isolates into two independently diverging groups (Fig. 4B, C, and D), accounting for 24 and 13\% (PC3), respectively, of the variability observed within the groups. However, certain isolates from the West African nation of Togo showed an interesting pattern of variance within their population (Fig. 4D). An inspection of principal components beyond PC3 did not identify additional variance (beyond 12\%) within the sample groups, suggesting an admixture between groups/populations.

Relationship between SNPs and virulence of isolates. The virulence spectrum and differences in disease scores among the seven clades derived from the SNP phylogeny were compared using standard least square regression method (Fig. 5). The data provide evidence of an association between genetic diversity and virulence among isolates. Across the seven genetic clades, the mean disease scores ranged from 1.2 to 3.7. Over half of the isolates in clades 1, 3, and 4 showed virulence to some of the rice genotypes and had disease mean scores ranging between 3.2 and 3.7. Generally, the majority $(77 \%)$ of the isolates in the top three clades were from West Africa. The distribution of the isolates in the three most virulent clades was as follows: clade 1 ( $n=1$, East Africa; $n=29$, West Africa), clade 3 ( $n=0$, East Africa; $n=7$, West Africa), and clade 4 ( $n=10$, East Africa; $n=0$, West Africa) (Fig. 5). Mean disease scores did not differ between the top two clades, clades 3 and $4(P>0.05)$. Clades 5 and 6 consisted mainly of avirulent isolates, with virulence scores ranging from 18 to $31 \%$ and disease mean score of less than 3 .

Genetic relatedness of $M$. oryzae based on vegetative compatibility. Characterization of the fungal population based on vegetative compatibility showed that there were no similar compatible groups among countries. Generally, the number of isolates within a VCG was affected by the challenges in obtaining testers within isolates of a country. One VCG was observed for isolates from each of the following countries: Benin, Burkina Faso, and Togo. While two VCGs were identified for isolates from Ghana,
Tanzania, and Uganda, respectively. For Kenyan isolates, there were three VCGs (Table 5). For countries with one VCG, Burkina Faso had the largest sample size $(n=15)$. For countries with more than one VCG, only Nigeria had the majority of the isolates (76\%) falling in one of the two VCGs. Similar proportions of isolates were observed within the VCGs of Tanzania, Kenya, Uganda, and Ghana (Table 5).

Relationship between VCG, virulence, and SNPs of isolates. A comparison of mean disease scores showed significant differences $(P<0.0001)$ in VCGs across the countries. The least mean

TABLE 5. Comparison of virulence spectrum among vegetative compatibility groups (VCG) of isolates of Magnaporthe oryzae collected from Africa ${ }^{y}$

\begin{tabular}{llllcc}
\hline & & & \multicolumn{3}{c}{ Disease score (0-9 scale) } \\
\cline { 4 - 6 } & & & \multicolumn{3}{c}{$\begin{array}{c}\text { Confidence interval } \\
(95 \%)\end{array}$} \\
\cline { 4 - 6 } Country & VCG & Isolates $(n)$ & LSM \pm SE $^{\text {z }}$ & Lower 95\% & Upper 95\% \\
\hline Ghana & GH-1 & 1 & $4.8 \pm 0.3 \mathrm{a}$ & 4.2 & 5.5 \\
Togo & TG-1 & 3 & $4.3 \pm 0.2 \mathrm{ab}$ & 4.0 & 4.7 \\
Tanzania & TZ-2 & 5 & $4.1 \pm 0.1 \mathrm{abc}$ & 3.8 & 4.4 \\
Tanzania & TZ-1 & 8 & $3.6 \pm 0.1 \mathrm{bcd}$ & 3.4 & 3.8 \\
Nigeria & NG-2 & 4 & $3.5 \pm 0.2 \mathrm{cde}$ & 3.1 & 3.8 \\
Burkina & & & & & \\
Faso & BN-1 & 2 & $3.4 \pm 0.2 \mathrm{bcdef}$ & 2.9 & 3.9 \\
Nigeria & NG-1 & 13 & $3.3 \pm 0.1 \mathrm{de}$ & 3.1 & 3.5 \\
Kenya & KE-3 & 3 & $3.1 \pm 0.2 \mathrm{def}$ & 2.7 & 3.5 \\
Kenya & KE-4 & 2 & $3.0 \pm 0.2 \mathrm{defg}$ & 2.6 & 3.5 \\
Ghana & GH-2 & 1 & $2.8 \pm 0.3 \mathrm{cdefg}$ & 2.2 & 3.5 \\
Kenya & KE-1 & 5 & $2.7 \pm 0.1 \mathrm{fg}$ & 2.4 & 2.9 \\
Uganda & UG-2 & 2 & $2.6 \pm 0.2$ efg & 2.2 & 3.1 \\
Uganda & UG-1 & 1 & $2.3 \pm 0.3$ efg & 1.7 & 3.0 \\
Burkina & & & & & \\
Faso & BF-1 & 15 & $2.3 \pm 0.1 \mathrm{~g}$ & 2.1 & 2.4 \\
\hline
\end{tabular}

${ }^{\mathrm{y}}$ Virulence spectrum was assessed based on response of a panel of rice germplasm $(n=42)$ to a collection of M. oryzae from Africa on a disease score scale of 0 to 9 .

${ }^{\mathrm{z}}$ Least square mean \pm standard error of disease scores. Means were separated and compared using Tukey's honest significant difference test at $\alpha=0.05$. Means followed by the same letter do not differ significantly.

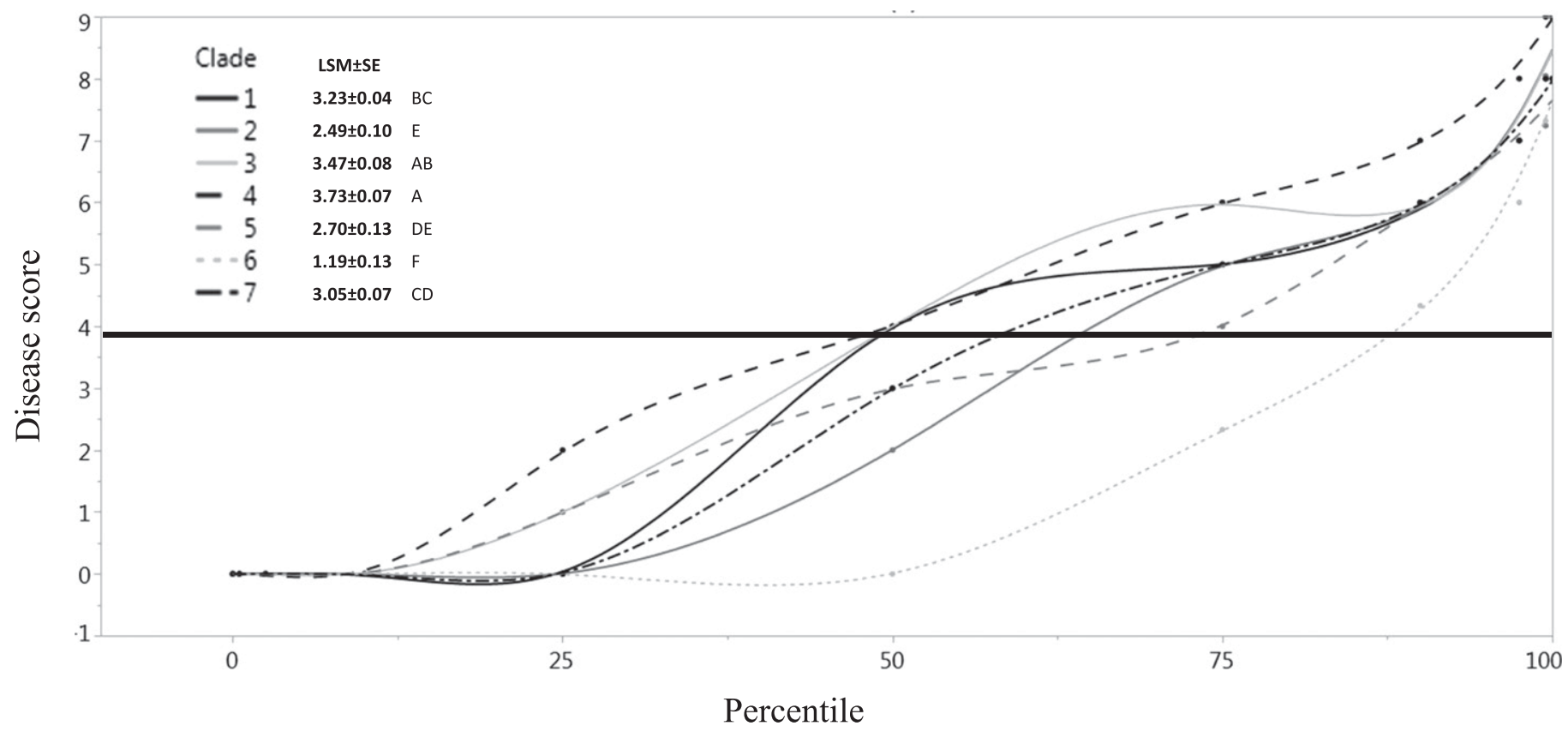

Fig. 5. Percentiles of rice blast disease scores assessed against the rice panel $(n=42)$ and a comparison of least square means of the scores among clades. Clades are denoted by symbols in the line graph. Horizontal line cutting at 4 in the y axis shows the least percentile at which virulent isolates were observed in each clade. Disease was scored on a scale of 0 to 9 , where $0=$ no symptom, 1 to $3=$ varying degrees of hypersensitive reaction, and 4 to $9=$ increasing severity of blast disease. Comparison of means of disease score based on Tukey's honest significant difference test. LSM, least square means. SE, standard error. Means followed by similar letters do not differ significantly $(\alpha=0.05)$. 
disease scores were observed in Ugandan and Kenyan VCGs, while the highest were observed in Togo, Tanzanian, and Ghanaian VCGs (Table 5). Because some VCGs had few samples, further investigations were conducted to ascertain whether isolates within an individual VCG had similar disease reactions based on data from three VCGs (Fig. 6). A sorted graphical representation showed that the majority of the tested isolates in BF-1 had a high similarity in disease reactions and were mainly avirulent to the rice lines. However, one isolate of the BF-1 was highly virulent and showed a similar disease reaction to the rice lines as with most of the isolates in TZ-1 (Fig. 6). The reaction patterns of most isolates in NG-1 and TZ-1 were similar (Fig. 6). The similarity in disease reactions of the isolates within VCGs was confirmed by using a cluster analysis of the isolates based on Unweighted Pair Group with Arithmetic Mean method (Fig. 7A).

A cluster analysis based on disease reactions of a subset of isolates from three VCGs showed no similarity with the SNP phylogenetic clustering of the same isolates (Fig. 7A and B). Furthermore, isolates from the same VCG did not reveal any obvious clustering based on SNP phylogenetic analysis (Fig. 7B).

\section{DISCUSSION}

Among the major causes of demand deficit in African rice production are the significant losses due to rice blast disease. In order to devise a sustainable blast control strategy through breeding, a diverse collection of $M$. oryzae was characterized using three independent methods in the current study. This paper provides a report of the most robust characterization of an African collection of M. oryzae using rice blast differentials, vegetative compatibility analysis, and GBSderived SNP phylogeny. By analyzing rice differential lines with known blast resistance genes, blast disease resistance genes that could be combined or introduced into African rice germplasm to achieve durable resistance were identified. By including African cultivars in the pathotyping panel, the appropriate adapted backgrounds into which promising $R$-genes could be introduced were also identified. By assessing vegetative compatibility and SNP phylogeny using GBS data, the genetic relatedness of the pathogen collection from East and West African regions was also inferred, providing further information on appropriate breeding strategies.

The characterized African blast pathogen collection consisted of genetically diverse genotypes of $M$. oryzae whose virulence ranged from complete avirulence in five Nigerian isolates to virulence on $80 \%$ of the rice genotypes by one Ghanaian isolate. Based on SNP phylogeny of the subset of pathogen collection and the eight international isolates, African isolates clustered into seven unique clades which differed significantly in virulence spectra. Interestingly, the majority of the isolates from West Africa clustered together with the Colombian isolate in clade 1, while the majority of isolates from East Africa clustered with the isolate from the United States in clade 7, and another reasonable proportion uniquely clustered in clade 4 . Analysis of the association between genetic relatedness and virulence showed that the majority (77\%) of the isolates in the three clades with the highest mean disease scores were from West Africa. Although the likelihood ratio tests showed a marginal similarity in the virulence between the two regions, the observed trends imply a more advanced evolution of distinct virulence forms in West than in East Africa. West Africa has a longer history of rice production than East Africa, consistent with this idea. Continued rice cultivation, trade, and breeding efforts of diverse rice genotypes may for instance have resulted in a gradual shift in virulence spectrum, with an emergence of distinct groups of avirulent and highly virulent strains across the region. For example, the observed clonal lineages in isolates from Nigeria could be indicative of a small genetic variation in rice cultivated in the country, or perhaps a sampling bottleneck. The observed differences in virulence among the $M$. oryzae genetic clades imply that certain SNPs could be useful in identification of the genomic regions associated with avirulence or virulence. The observed atypical growth patterns and the inability to infect any rice genotype by the five Nigerian isolates were unexpected and require further investigation.

This study shows the utility of the IRBLs in characterization of the virulence spectrum of $M$. oryzae and its global shifts. Use of

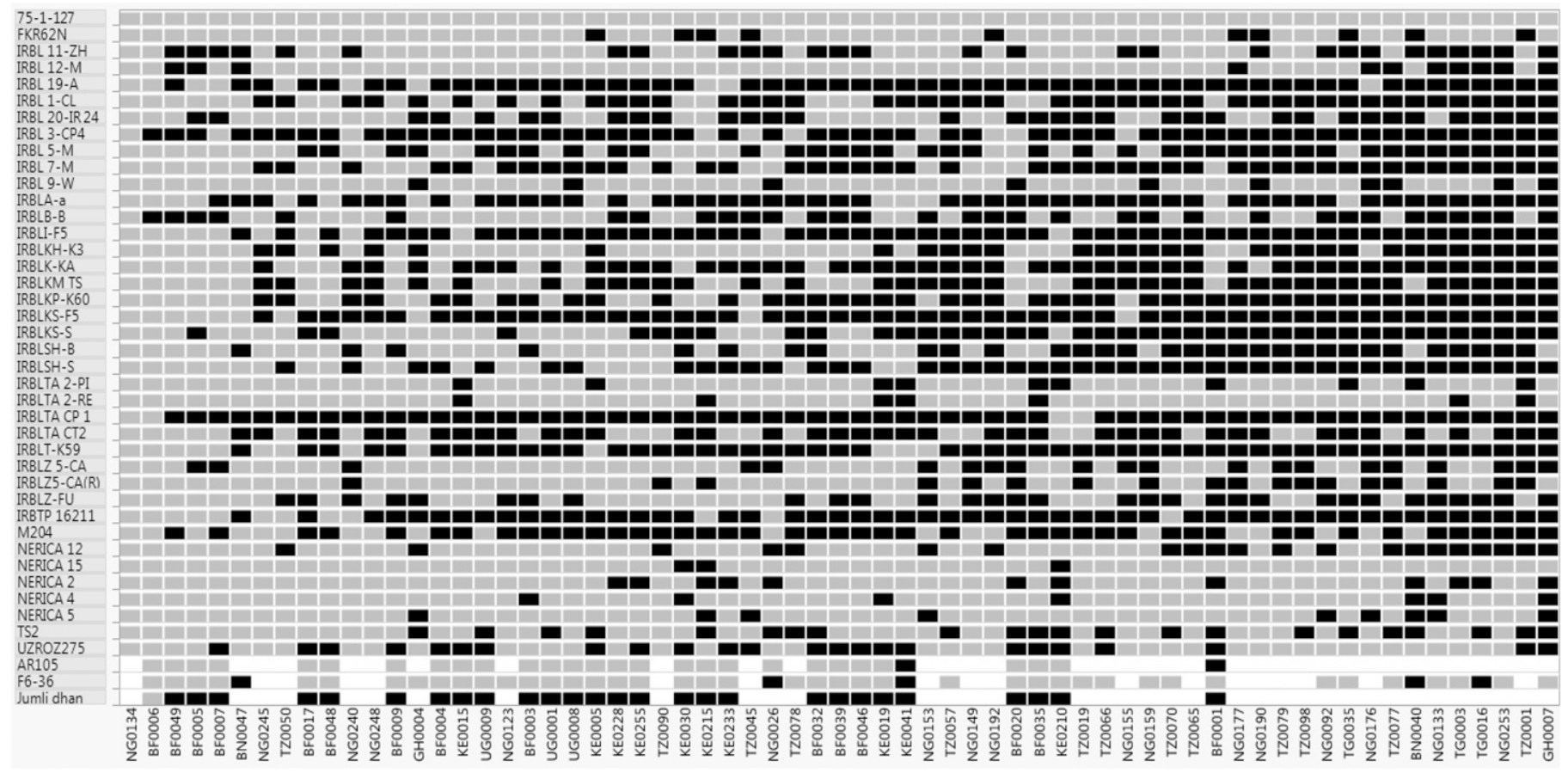

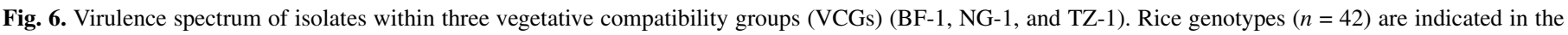

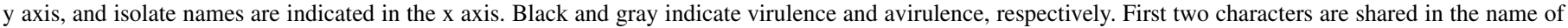
the isolate and the VCG. 
existing $R$-genes in pathotyping provides a standard comparison of the virulence spectrum for blast populations across different geographical locations and a cost-effective breeding strategy which reduces the time of $R$-gene discovery efforts. To reduce the chances of $R$-gene breakdown, $R$-genes should be pyramided into adapted crop plants (Miah et al. 2013). To attain durable resistance for African rice, the effective $P i 9$ gene could be combined with a subset of others and bred into adapted African cultivars. $P i 9$ was identified and cloned using map-based strategy from $O$. minuta and has been found to confer resistance against a broad range of $M$. oryzae strains globally. (Qu et al. 2006). Previous studies involving pathogen collections from Benin, Burkina Faso, Guinea, Mali, and Nigeria also showed that $P i 9$ was effective in those countries. In spite of its recognized effectiveness against a wide range of $M$. oryzae isolates, the utility of $P i 9$ in rice breeding programs is not well established. In the current study, combining Pi9 from the donor line 75-1-127 and Pita2 $R$-genes into cultivar F6-36 or into NERICA 15 could achieve durable blast resistance in West Africa. Similarly, durable blast resistance for East Africa could be achieved by introducing $P i 9$ and Pita2 or Pi12 into NERICA 2, and other widely cultivated varieties such as Basmati 370 and Basmati 217. To understand their performance under field conditions, pre-breeding rice populations developed through the proposed strategy should be evaluated in blast disease hotspot areas of East and West Africa.
Differences were observed in the response of rice cultivars carrying the same blast $R$-genes and also in binary disease reactions when maximum scores were used instead of means. IRBL9-W is a differential line carrying $P i 9$ which was introgressed from line 75-1-127, yet the line conferred resistance to a marginally lower percentage of $M$. oryzae isolates compared with the donor line. The possible causes of the observed differences in the two rice genotypes containing Pi9 include existence of additional unidentified resistance loci in the donor line and/or bottlenecks in introgression of the resistance loci into the new genetic background. Previous pathotyping effort at IRRI did not show major differences between the donor and the IRBL line carrying Pi9. Different types of genetic interactions between the introgressed and the neighboring loci could also affect the expression of the introgressed gene. Furthermore, the extent of the genetic interactions could differ depending on the type of alleles and their location on the recurrent line. Differences arising from use of maximums could have been caused by inoculum failure and/or escapes. The proposed pyramiding of multiple promising $R$-genes into somewhat resistant and adapted African cultivars overrules the caveats associated with the observed genotypic responses in the current study.

African rice cultivars AR105 (O. glaberrima), F6-36, NERICA 4 , and NERICA 15 were found to be resistant to the majority ( 90 to $96 \%$ ) of isolates tested. These findings are in agreement with previous reports of $M$. oryzae isolates from West Africa on NERICA

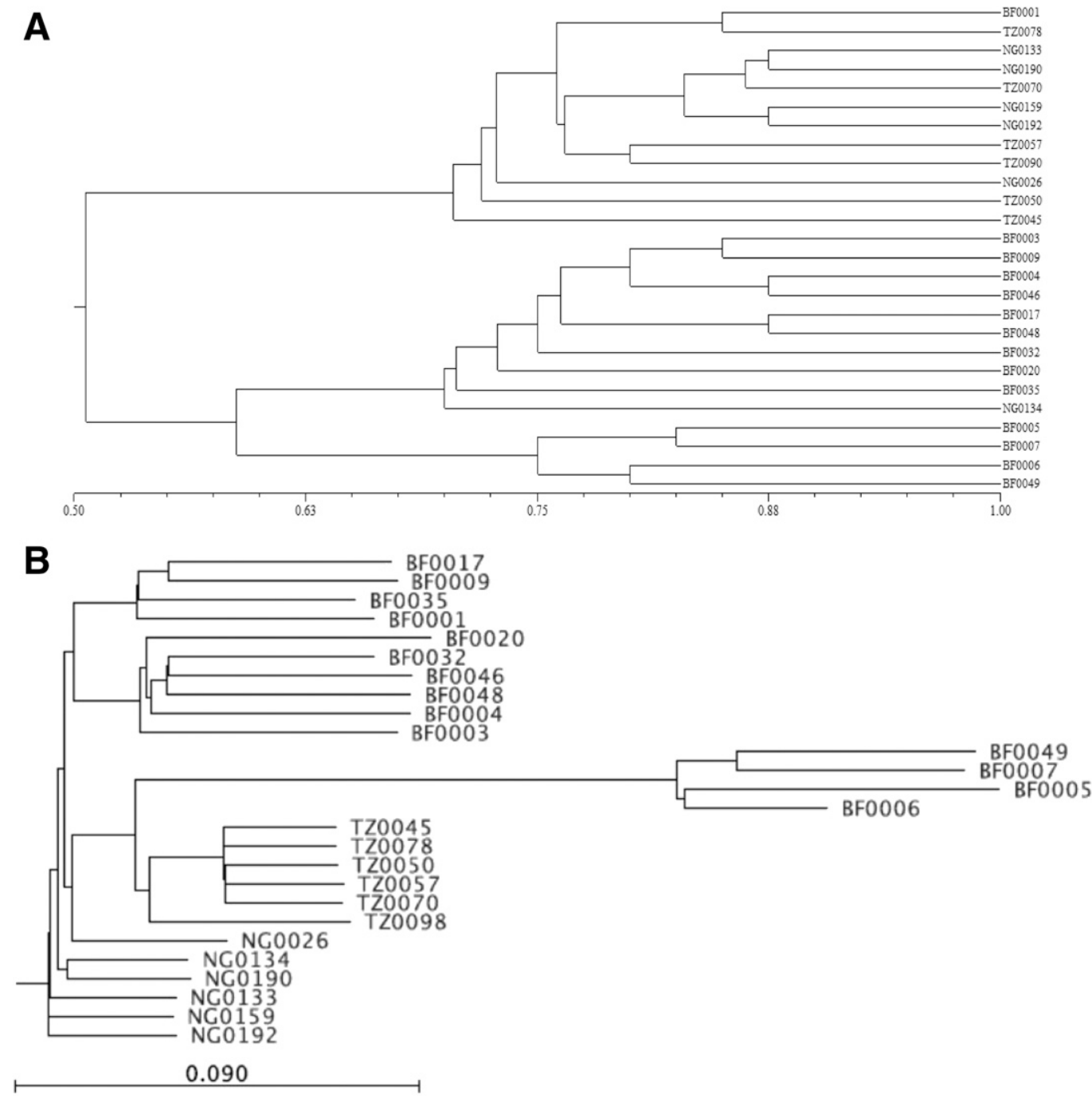

Fig. 7. Cluster analysis of similarity based on A, single nucleotide polymorphism phylogeny. B, Disease reactions of isolates within three vegetative compatibility groups (VCGs) (NG-1, TZ-1 and BF-1). The two letter prefixes in the names of the isolates correspond to the VCG names. Binary disease reactions, virulence and avirulence, of a rice genotype panel $(n=43)$ which was artificially inoculated African isolates of Magnaporthe oryzae. Dendrogram was generated using Unweighted Pair Group with Arithmetic Mean method (NTSYS, 2.5). 
cultivars (Loria 2009). African breeders developed the NERICA varieties based on adaptation and resistance to blast by crossing $O$. glaberrima and $O$. sativa (Singh et al. 2000). The resistance of NERICA and other interspecific cultivars to blast might have been derived from the $O$. glaberrima parents that are known to be highly resistant to blast (Jones et al. 1997). The observed resistance in these African cultivars implies that durable blast resistance could be achieved through breeding programs aimed at improving through selection or enrichment using $R$-genes identified in other parts of the world.

Distinct VCGs were observed in isolates from individual countries. The country-specific VCGs could be due to restricted clonal reproduction and a little or no movement of inoculum over wide geographical areas. The low genetic diversity in $M$. oryzae populations from Africa has previously been reported (Nutsugah et al. 2008; Onaga et al. 2015). Although VCG loci are associated with nutrient utilization, no significant differences in the virulence spectrum were found in isolates belonging to different groups within a country. Furthermore, the SNP phylogeny of isolates from three different VCGs did not reveal similarity with the cluster dendrogram of disease reactions based on the rice panel $(n=42)$. Taken together, these findings show that the VCGs were not associated with the virulence of $M$. oryzae and that the genetic relatedness between members in a VCG may not be obvious; members of the same VCG could, for example, differ in multiple SNPs. It should be noted that there were difficulties in obtaining testers in the current study. Lack of unique testers reduces the number of isolates to be characterized, limiting the inferential power.

In summary, this study shows that the previously recognized resistance genes can be introduced into adapted African rice cultivars in a breeding strategy to deliver durably resistant rice cultivars for the rice growers in the two regions of sub-Saharan Africa. The efficiency of such a program would be enhanced by using a marker assisted $R$-gene introgression, or a transgenic approach, if varieties derived from the latter strategy would be deregulated by individual countries. A program is underway to introgress the promising $R$-genes identified in the current study into African rice varieties through marker-assisted breeding. Although the number of isolates from some countries was low, the virulence spectrum reported in the current study also favors a regional breeding strategy, for East and West Africa. It is already clear that different gene combinations will be necessary for maximal exclusion and control of the prevailing pathogen population. Further analysis of the pathogen population will provide greater resolution and planning of effective disease control strategies for both regions. Additionally, based on the observed association between genetic relatedness (SNP clades) and virulence, there is a need to conduct a genome-wide analysis to mine for additional avirulence genes to enhance monitoring of the virulence spectrum of the African $M$. oryzae population. Future pathotyping efforts should therefore involve more pathogen collections from countries which had small samples, such as Ghana, Mali, and Uganda. For effective control of rice blast through breeding, disease surveillance strategies should be integrated with rice breeding programs. Such combined efforts would ensure that the genotypic characterization of the prevailing rice blast pathogen population can be used to guide the deployment of sets of disease resistance genes in African rice cultivars to attain effective control of rice blast across Africa.

\section{ACKNOWLEDGMENTS}

This research was supported by the Sustainable Crop Production Research for International Development (SCPRID) initiative, grant BB/ J012157/1, funded jointly by the Biotechnology and Biological Sciences Research Council (BBSRC), the Department for International Development (DFID) and (through a grant awarded to BBSRC) the Bill \& Melinda Gates Foundation, with additional funding from the Department of Biotechnology (DBT) of India's Ministry of Science and Technology. We thank D. Tharreau (Centre de Coopération Internationale en Recherche Agronomique pour le Développement, CIRAD, Montpellier, France) for provision of some of the isolates that were characterized in the current project. We also thank the technical staff in the labs of J. C. Correll, T. Mitchell, N. Talbot, and G.-L. Wang for their support at different stages of the research effort.

\section{LITERATURE CITED}

Bidaux, J. M. 1978. Screening for horizontal resistance to rice blast (Pyricularia oryzae) screening for horizontal resistance to rice blast (Pyricularia oryzae) in Africa. Pages 154-174 in: Rice in Africa: Proceedings of a Conference held at the International Institute of Tropical Agriculture Ibadan, Nigeria. I. W. Buddenhagen, G. J. Persley, and IITA, eds. Academic Press, Massachusetts.

Correa-Victoria, F. J., and Zeigler, R. S. 1993. Pathogenic variability in Pyricularia grisea at a rice blast hot-spot breeding site in eastern Colombia. Plant Dis. 77:1029-1035.

Correll, J. C., Harp, T. L., Guerber, J. C., Zeigler, R. S., Liu, B., Cartwright, R. D., and Lee, F. N. 2000. Characterization of Pyricularia grisea in the United States using independent genetic and molecular markers. Phytopathology 90:1396-1404.

Correll, J. C., Klittich, C. J. R., and Leslie, J. F. 1987. Nitrate non-utilizing mutants of Fusarium oxysporum and their use in vegetative compatibility tests. Phytopathology 77:1640-1646.

de Wit, P. 1992. Molecular characterization of gene-for-gene systems in plant-fungus interactions and the application of avirulence genes in control of plant pathogens. Annu. Rev. Phytopathol. 30:391-418.

Fukuta, Y., Araki, E., Yanoria, M. J. T., Imbe, T., Tsunematsu, H., Kato, H., Ebron, L. A., Mercado-Escueta, D., and Khush, G. S. 2004. Development of differential varieties for blast resistance in IRRI-Japan collaborative research project. Pages 229-233 in: Rice Blast: Interaction with Rice and Control. S. Kawasaki, ed. Springer, Netherlands.

Glaubitz, J. C., Casstevens, T. M., Lu, F., Harriman, J., Elshire, R. J., Sun, Q., and Buckler, E. S. 2014. TASSEL-GBS: A high capacity genotyping by sequencing analysis pipeline. PLoS One 9e90346.

Jacobson, D. J., and Gordon, T. R. 1990. Variability of mitochondrial DNA as an indicator of relationships between populations of Fusarium oxysporum f. sp. melonis. Mycol. Res. 94:734-744.

Jones, M. P., Dingkuhn, M., Aluko, G. K., and Semon, M. 1997. Interspecific $O$. sativa L. x O. glaberrima Steud. progenies in upland rice improvement. Euphytica 92:237-246.

Leslie, J. F. 1993. Fungal vegetative compatibility. Annu. Rev. Phytopathol. $31: 127-150$.

Li, H., and Durbin, R. 2009. Fast and accurate short read alignment with Burrows-Wheeler transform. Bioinformatics 25:1754-1760.

Linares, O. F. 2002. African rice (Oryza glaberrima): History and future potential. Proc. Natl. Acad. Sci. USA 99:16360-16365.

Liu, G., Lu, G., Zeng, L., and Wang, G. L. 2002. Two broad-spectrum blast resistance genes, $P i 9(t)$ and $P i 2(t)$, are physically linked on rice chromosome 6. Mol. Genet. Genomics 267:472-480.

Loria, R. 2009. Interspecific Oryza sativa L. $\times$ O. glaberrima Steud. progenies in upland rice improvement. Streptomyces scabies: Mapping a novel path to pathogenicity. Phytopathology 99:S167.

McDonald, B. A., and Linde, C. 2002. Pathogen population genetics, evolutionary potential, and durable resistance. Annu. Rev. Phytopathol. 40: 349-379.

Miah, G., Rafii, M. Y., Ismail, M. R., Puteh, A. B., Rahim, H. A., Asfaliza, R., and Latif, M. A. 2013. Blast resistance in rice: A review of conventional breeding to molecular approaches. Mol. Biol. Rep. 40:2369-2388.

Milgroom, M. G., Jimenez-Gasco, M. M., Olivares-Garcia, C., Drott, M. T., and Jimenez-Diaz, R. M. 2014. Recombination between clonal lineages of the asexual fungus Verticillium dahliae detected by genotyping by sequencing. PLoS One 9:e106740.

Nutsugah, S. K., Twumasi, J. K., Chipili, J., Sere, Y., and Sreenivasaprasad, S. 2008. Diversity of the rice blast pathogen populations in Ghana and strategies for resistance management. Plant Pathol. 7:109-113.

Onaga, G., Wydra, K., Koopmann, B., Sere, Y., and von Tiedemann, A. 2015. Population structure, pathogenicity, and mating type distribution of Magnaporthe oryzae isolates from East Africa. Phytopathology 105:1137-1145.

Qu, S., Liu, G., Zhou, B., Bellizzi, M., Zeng, L., Dai, L., Han, B., and Wang, G.-L. 2006. The broad-spectrum blast resistance gene $P i 9$ encodes a nucleotide-binding site-leucine-rich repeat protein and is a member of a multigene family in rice. Genetics 172:1901-1914.

R Core Team. 2015. R: A Language and Environment for Statistical Computing. R Foundation for Statistical Computing, Vienna, Austria.

Sèrè, Y., Akator, K., and Onasanya. 2008. Major rice diseases and control. Pages 96-97 in: NERICA: The New Rice for Africa-A Compendium. E. A. G. Somado and S. O. Keya, eds. Africa Rice Center, Cotonou, Benin. 
Sèrè, Y., Fargette, D., Abo, E., Wydra, E., Bimerew, M., Onasanya, A., and Akator, S. 2013. Managing major rice diseases in Africa. Pages 213-228 in: Realizing Africa's Rice Promise. M. C. S. Wopereis, D. E. Johnson, N. Ahmadi, E. Tollens, and A. Jalloh, eds. CABI, Wallingford, UK.

Sèrè, Y., Onasanya, A., Afolabi, A., Mignouna, H. D., and Akator, K. 2007. Genetic diversity of the blast fungus, Magnaporthe grisea (Hebert) Barr, in Burkina Faso. Afr. J. Biotechnol. 6:2568-2577.

Saito, K., Nelson, A., Zwart, S. J., Niang, A., Sow, A., Yoshida, H., and Wopereis, M. C. S. 2013. Towards a Better Understanding of biophysical determinants of yield gaps and the potential for expansion of the rice area in Africa. Pages 188-203 in: Realizing Africa's Rice Promise. M. C. S. Wopereis, D. E. Johnson, N. Ahmadi, E. Tollens, and A. Jalloh, eds. CABI, Wallingford, UK.

Saleh, D., Milazzo, J., Adreit, H., Fournier, E., and Tharreau, D. 2014. SouthEast Asia is the center of origin, diversity and dispersion of the rice blast fungus, Magnaporthe oryzae. New Phytol. 201:1440-1456.

Singh, B. N., Jones, M. P., Fomba, S. N., Sèrè, Y., Sy, A. A., Akator, K., Ngninbeyie, P., and Ahn, S. W. 2000. Breeding for blast resistance in rice in West Africa. Pages 112-127 in: Advances in Rice Blast Research.
D. Tharreau, M. H. Lebrun, N. J. Talbot, and J. L. Notteghem, ed. Springer, Dordrecht, the Netherlands.

Singh, W. H., Kapila, R. K., Sharma, T. R., and Rathour, R. 2015. Genetic and physical mapping of a new allele of Pik locus from japonica rice 'Liziangxintuanheigu'. Euphytica 205:889-901.

Tharreau, D., Fudal, I., Andriantsimialona, D., Santoso, Utami, D., Fournier, E., Lebrun, M. H., and Notteghem, J. L. 2009. World population structure and migration of the rice blast fungus, Magnaporthe oryzae. Pages 209-215 in: Advances in Genetics, Genomics and Control of Rice Blast Disease. W. Xiaofan and B. Valent, eds. Springer, Dordrecht, the Netherlands.

Valent, B., and Chumley, F. G. 1991. Molecular genetic analysis of the rice blast fungus, Magnaporthe grisea. Annu. Rev. Phytopathol. 29:443-467.

Zhai, L. 2012. Genotypic and phenotypic diversity of Pyricularia oryzae in the contemporary rice blast pathogen population in Arkansas. University of Arkansas, Fayetteville.

Zhu, Y. Y., Fang, H., Wang, Y. Y., Fan, J. X., Yang, S. S., Mew, T. W., and Mundt, C. C. 2005. Panicle blast and canopy moisture in rice cultivar mixtures. Phytopathology 95:433-438. 